\title{
A Challenging Issue for both Patients and Physicians: Breaking Bad News in Oncology
}

\author{
Dilek ANUK, ' (D) Güler BAHADIR²
}

'Department of Psychiatry, İstanbul University, İstanbul Faculty of Medicine, Consultation Liaison Division, İstanbul-Turkey

${ }^{2}$ Department of Psychiatry, İstanbul University, İstanbul Faculty of Medicine, İstanbul-Turkey

\begin{abstract}
SUMMARY
Providing the patients with negative information about diagnosis, treatment, and prognosis, in other words breaking bad news, is a complicated process for both the patient and the physician. The oncologists often should break the bad news to patients and their relatives. Bad news in the field of oncology often includes the following processes: telling the diagnosis of cancer, providing information about recurrence or metastasis according to the prognosis of the disease, saying that there is nothing left to do medically, and ultimately telling the relatives of the patient the death of the patient. A negative diagnosis or a negative improvement in prognosis should be explained to the patient (sometimes to the patient's relative) with care, empathic and sensitive attitude because a person is emotionally vulnerable while receiving bad news about his/her health or health of a relative. We will focus, in this article, on the importance of breaking bad news as part of clinical practice in oncology, and we will briefly introduce the protocols developed for the proper conduct of breaking bad news and provide information about what the physician should do in the process of breaking bad news by considering the basic features of breaking bad news protocols.
\end{abstract}

Keywords: Bad news; breaking bad news protocols; communication; oncology.

Copyright @ 2020, Turkish Society for Radiation Oncology

\section{Introduction}

"The task of breaking bad news is a testing ground for the entire range of our professional skills and abilities. If we do it badly, the patients or family members may never forgive us; if we do it well, they will never forget us."

\section{R. Buckman (1992)}

There are several basic definitions of bad news, which have various difficulties concerning both breaking and receiving it. Buckman [1] defines the bad news as "news that will seriously change one's outlook on the future." Ptacek and Eberhardt [2] define it as "the information that causes cognitive, behavioral, and emotional deficits in the person receiving the news." As in all medical fields, the bad news is an essential part of clinical practice in the field of oncology. Bad news in the field of oncology often includes the following processes: telling the diagnosis of cancer, providing information about recurrence or metastasis according to the prognosis of the disease, saying that there is nothing left to do medically, and ultimately telling the relatives of the patient the death of the patient. Many cancer patients may remember very clearly how they were told about their diagnosis, even if they remembered very little of the speech given after being told the diagnosis.[3]

Bad news in medicine presents a wide range of challenges both for the person receiving the news and for the physicians breaking it. Having bad news about 
a medical condition may cause negative feelings and worries about the future. In addition, not only the bad news itself but also the way the news is given affects the person's perception of the news, his/her coping behavior, his emotional reactions to the disease, his compliance with the treatment and his confidence in the physician. [4,5] Thus, the communication style that the physician uses during bad news is very important.

Professor Doctor Füsun Yarış, a physician and a faculty member, described the bad news about her as follows: "Was it an advantage for me to be a physician? Maybe it wasn't. Actually, I was also an ordinary person and a regular patient. I was deserving to get the bad news in the right way just as much as anyone. However, with the ultrasound probe on me, the physician said to me, "Ah yes, Füsun, this is a terrible thing, you have two huge masses. Moreover, there is acid as well, and this may be stage 4, I must check the other organs." The physician who had carried out the examination had so forgotten the necessities of his profession and ignored the patient, so he could say these words the fellow doctor next to him: "Come and look. You rarely see such an image." Just 10 minutes ago, I was Professor Füsun or his colleague Füsun. But at that moment, I was transformed into an entity called stage $3 \mathrm{C}$, maybe stage 4 . Your whole life changes at that moment, "If I were alone at home that night, I would have committed suicide".[6] These words may show how destructive bad news can be for the person if it is not given with a communication styles appropriately and in a sensitive manner.

We should note that $90 \%$ of the physicians in the United States preferred not to tell the patient the diagnosis of cancer in the 1950s and 60s. Until the concept of the patient's right to information emerged, Hippocrates' motto was widely accepted: "saying a bad diagnosis increases mental anguish and psychological pain, so protect patients." Today, in Western countries, most physicians prefer to tell the patient the diagnosis of the cancer. However, this rate is low in eastern countries.[7] The most important reason for this difference is that the patient-centered relationship model based on physician-patient cooperation has stood out as opposed to the paternalistic/physician-centered relationship model. Another reason for the increase in the number of physicians telling patients about the diagnosis of cancer is that there are patient rights regulations that include the right to information, including the right to receive bad news. Despite the legal regulations, there are still different opinions about breaking bad news. In a study with the participation of 304 physicians, Özkırış et al. found that the rate of physicians who agreed with the idea that the diagnosis of cancer was clearly told to the patient was as follows: $77.6 \%$, if they are the patients themselves; $55.6 \%$ if the patient is a relative; and $51 \%$ if the patient is an adult person. [8] This result suggests that some physicians are reluctant to break the bad news to the patient. One of the most important factors affecting this attitude is the worry and fear of not being able to cope with the intense feelings and behaviors that the patient/patient's relatives will experience after breaking the bad news. Other factors that have been found to negatively affect the process of breaking bad news include overprotective attitude of the families, physician's lack of knowledge or training on breaking bad news, burnout and fatigue levels, time constraints, lack of experience, fear of harm to the patient, fear of being accused by patients or their relatives, and worry that patients may be negatively affected and lead to despair and even poor prognosis.[1,4,9-11] The stress experienced by the physician who breaks the bad news may be related to the emotional burden of the news as well as the awareness of the physician about his/her emotional reactions and inner world. [12,13] Confronting one's own emotions, especially death concerns, is one of the significant challenges in the process of breaking bad news. $[5,14,15]$ In this context, E. Kübler-Ross (1973) asked the following question: "Is our concentration on equipment, on blood pressure, our desperate attempt to deny the impending end, which is so frightening and discomforting to us that we displace all our knowledge onto machines, since they are less close to us than the suffering face of another human being, which would remind us once more of our lack of omnipotence, our own limitations and fallibility and, last but not least perhaps, our own mortality??"[16]

Most of the patients prefer to learn the diagnosis and treatment information. Fujimori et al. (2007), in their research, found that approximately $90 \%$ of the patients wanted to discuss their current medical condition and treatment options with the physicians.[5] Bostanoğlu, Fesci and Ünal (2011) conducted a study with 327 patients and determined the preferences of the patients in the context of the bad news as follows: $36.7 \%$ of the patients were asked to know everything, $10.6 \%$ of them wanted to know as much as they could understand, $4.6 \%$ wanted to know only the good news and $2.1 \%$ of them wanted to learn the prognosis.[17] A qualitative meta-analysis study reported that cancer patients wanted to receive the bad news in an appropriate environment and in accordance with their personal preferences and also to meet their psychological needs. [18] The education level of the majority of these patients was a primary school and below. Along with age and education, socio-cultural factors also determine the demands of the patients concerning learning the diagnosis and treatment information. 


\section{Breaking bad news protocols}

The way bad news is given is as important as breaking the bad news. Breaking bad news protocols gain importance in this context. Considering the critical importance of bad news reporting, several researchers have developed breaking bad news protocols to establish a standardized approach.

The most commonly used protocols are listed below:

- The six-step protocol [19]

- The SPIKES protocol [20]

- ABCDE protocol [21]

- BREAKS Protocol [22]

Table 1 presents the stages of commonly used breaking bad news protocols. Although there are differences between them, there are some common points highlighted in all breaking bad news protocols. The preparation that should be handled by physicians before breaking bad news is the first step that is important in all protocols. Investigating patients' awareness of their illnesses, assessing patients' willingness to receive information, and providing an appropriate environment for breaking bad news are other common issues in the protocols. Another issue that stands out in the protocols is the establishment of effective communication while breaking bad news and the continuation of this thereafter. In all protocols, the points to be considered in the context of communication with the patients are: to use a simple and non-technical language; to show respect; to empathize with the patient, and to break the bad news with a step by step process. Despite the progress achieved so far, more attention is needed in the medical education process and in vocational training to ensure that these protocols are adequately involved in daily practice.[23]

Considering the critical common features in the protocols, the course of actions that the physician should follow in the process of breaking bad news is listed below:

Who should give the bad news? The physician who knows the patient communicates with the patient and

Table 1 Stages of breaking bad news protocols

\section{The six-step Protocol}

(Robert Buckman-1992)

\section{Getting started:}

Prepare for the news, start the conversation

\section{Finding out how much the patient knows:}

To investigate what the patient knows about his/her illness

\section{Finding out how much} the patient wants to know: To learn how much information the patient wants to have

\section{Sharing the information:}

To share information/bad news with the patient.

\section{Responding to the} patient's feelings: To allow the patient to express his/her feelings.

6. Planning and follow-through: To do planning about treatment options, and follow up.

\section{SPIKES Protocol}

(Baile et al. 2000)

Setting: Prepare the environment and get ready to listen

Perception: To learn the patient's judgment about his/her condition and the seriousness of his/her condition

Invitation-Information: Investigate what the patient wants to know and how much about the disease and prepare to give information.

Knowledge: Giving information, explaining medical facts

Explore-Empathize: To investigate the patient's emotions, and empathize with his/her reactions

Strategy and summary:

To determine and summarize treatment strategies

\section{ABCDE Protocol}

(Vandekieft G, 2001)

Advance preparation:

To make an excellent

preliminary preparation

Build a relationship:

To get in touch

with the patient

Communicate well:

Communicate effectively with the patient

Deal with patient and

family reactions: Dealing with the reactions of

the patient and/or family

Encourage and validate

emotions: Encouraging the patient to express his/her feelings
BREAKS Protocol

(Narayanan et al. 2010)

Background: To learn detailed information about the patient and the disease and to start preparing.

Rapport: To try to communicate effectively; to pay attention to issues, such as body language and eye contact

Explore: What does the patient know about the disease? What does he want to know? Whom does he want to be with when he is informed?

Announce: To start speaking with a short, clear, and understandable introductory sentence.

Kindling: Clarifying, allowing the patient to express his emotional reactions

Summarize: To summarize the situation, to give brief and concise information about treatment, to provide contact information, to suggest correct and scientific sources of information. 
has a trust relationship with the patient should break the bad news given that the bad news is given by the physician who has established a trust relationship with the patient can make the patients feel safe.

Who should be given the bad news? The patient himself or his relative(s)? The patient should be informed about the diagnosis, treatment, or positive/negative developments in the process concerning legal responsibility and to maintain a trust relationship. However, if the patient has previously declared that he does not want to know the diagnosis and treatment information with a legally valid document, the information can be given to his relatives. Families, in particular in the case of elderly patients, often try to ensure that the patient does not know about the disease. In this case, it is necessary to understand whether the family has hidden agendas (such as heritage issues). Furthermore, the patient has the right to learn any information about his life, regardless of age. Of course, the patient should be able-minded and not in any dementia process. Relatives or families of patients in our community mostly urge the physician not to provide the patient with accurate information. Interview(s) should be conducted with the patient to confirm whether such statements are realistic.

What kind of preparations should the physician make before breaking the bad news? The physician must have developed oral and nonverbal communication skills. A physician who makes eye contact with the patient, who uses the tone of voice and body language effectively, listens to the patient effectively, can be empathic with the patient, and has a sensitive attitude towards the patient's feelings and behaviors are indispensable for the breaking bad news process. The physician must have prepared himself to break the bad news concerning knowledge, emotion, and thought. He/she should know where to speak and where to remain silent and be prepared for possible questions from the patient. The patient should be asked if he/she wants someone from his family to accompany him/her during the process. If there is someone in the outpatient clinic with the patient, he/she should first be taken to a room alone and asked who they are and whether he/she wants them to be with her.

Where should the bad news be given? The place where bad news is given is of critical importance. Thus, a place should be identified that is quiet, calm, and where speech cannot be interrupted, and time should be allocated for this process. The interview should not be performed standing. If an inpatient is to be informed, efforts should be made to ensure privacy. If possible, another available room should be allocated, and the conversation should take place there.
What should be said, and how should it be said? The physician should try to find out what the patient knows before he/she breaks the bad news. What did the previous physicians say about the diagnosis and treatment processes? What does the patient think his/her disease is? What are his/her fears? Once these issues are clear, the physician should learn how much information the patient wants to have. For example, the following question may be asked: "Some patients want to have detailed information about their disease; others want shorter information. Which one do you prefer?" When starting to break the bad news, the physician is advised to use some transition sentences. For example, transition sentences, such as "if I had good news for you" or "I would have like to give you good news," will help to prepare the patient for the bad news. The physician should wait a short time after the transition sentence, summarize the findings and explain the diagnosis or relapse. Sentences should be short and concise. Descriptive sentences should not be overwhelmed by figures and statistics. It is essential to speak in a way that the patient can understand, instead of using medical jargon. It is also not recommended to give statistics related to a lifetime. "Quantitative statistics are for academic research, not for hospital rooms!" [24] Maintaining hope is also critical when breaking the bad news. Patients can usually remain silent at first and return to their inner world. Instead of consoling them, it is much more useful to encourage the patient to express his or her feelings. Active listening, empathy and sensitivity are the most beneficial behaviors for the good of the patient.

What should be done after breaking bad news? If the patient expresses his/her feelings or cries, it is necessary to wait and listen to the patient without interrupting. The physician should wait until he/she is sure that the patient has acknowledged the information received and then discuss treatment options. The physician may propose scientifically understandable resources and websites to direct the patient to the right sources of information or provide informative guides and brochures, if any. The physician shares his/her contact information or phone numbers of the hospital with the patient. Often, a single interview may not be enough for the patient to acknowledge the new information. If this is the case, a second interview can be planned. If the physician considers that the patient needs psychological support or psychiatric help, he or she may make some referrals. This sometimes happens at the request of the patient and sometimes at the advice of the physician.

As a result, how the bad news is given may have negative emotional and psychological consequences 
for both the patient and/or relatives and the physician. Therefore, the physician should plan all the steps, use the communication skills effectively and break the bad news in a sensitive and empathic manner.

\section{Conclusion}

Breaking bad news is an essential part of clinical practice in the field of oncology. The way the bad news is given is an experience that the patient will never forget. An empathetic and sensitive approach that considers the patient's feelings means that the patient more easily carries the burden of bad news. From the physician's perspective, developing selfawareness and a conscious approach to breaking bad news will help to establish a trust-based relationship with the patient. Moreover, the patient's compliance with the treatment will be high, the satisfaction of the physician will increase, and less stress will be experienced.

Peer-review: Externally peer-reviewed.

Conflict of Interest: The authors declare no conflict of interest.

Financial Support: None declared.

\section{References}

1. Buckman R. Breaking bad news: why is it still so difficult? Br Med J (Clin Res Ed) 1984;288 (6430):1597-9.

2. Ptacek JT, Eberhardt TL. Breaking bad news. A review of the literature. JAMA 1996;276(6):496-502.

3. Back T. Breaking bad news. Ethics in medicine: University of Washington School of Medicine Bioethics Web site. 2013. Access: (https://depts.washington.edu/ bhdept/ethics-medicine/bioethics-topics/detail/55.) Accessed 19 Nowember 2019.

4. Alshammary SA, Hamdan AB, Tamani JC, Alshuhil A, Ratnapalan S, Alharbi M. Breaking bad news among cancer physicians. J Health Spec 2017;5(4):66-72.

5. Fujimori $M$, Akechi $T$, Morita $T$, Inagaki $M$, Akizuki N, Sakano Y, et al. Preferences of cancer patients regarding the disclosure of bad news. Psychooncology 2007;16(6):573-81.

6. Cantürk S. Hekim gözüyle kanserle savaş (Prof. Dr. Füsun Yarış). Sabah Gazetesi 05.08.2013.

7. Bousquet G, Orri M, Winterman S, Brugière C, Verneuil L, Revah-Levy A. Breaking bad news in oncology: a metasynthesis. J Clin Oncol 2015;33(22):2437-43.

8. Özkıriş A, Güleç G, Yenilmez Ç, Musmul A, Yanaş M. Hekim Tutumları Üzerine Bir Çalışma: Ölüm ve Ölümcül Hastaya Yaklaşım. Düşünen Adam Psikiyatri ve Nörolojik Bilimler Dergisi 2011; 24(2):89-100.
9. Zolnierek KB, Dimatteo MR. Physician communication and patient adherence to treatment: A meta-analysis. Med Care 2009;47(8):826-34.

10. Sarafis P, Tsounis A, Malliarou M, Lahana E. Disclosing the truth: a dilemma between instilling hope and respecting patient autonomy in everyday clinical practice. Glob J Health Sci 2013;6(2):128-37.

11. Hahne J, Liang T, Khoshnood K, Wang X, Li X. Breaking bad news about cancer in China: Concerns and conflicts faced by doctors deciding whether to inform patients. Patient Educ Couns 2019;pii:S0738-3991(19)30362-3.

12. Fallowfield L, Jenkins V. Communicating sad, bad, and difficult news in medicine. Lancet 2004;363(9405):312-9.

13. Berney A, Carrard V, Schmid Mast M, Bonvin R, Stiefel F, Bourquin C. Individual training at the undergraduate level to promote competence in breaking bad news in oncology. Psychooncology. 2017;26(12):2232-7.

14. Ciałkowska-Rysz A, Dzierżanowski T. Personal fear of death affects the proper process of breaking bad news. Arch Med Sci 2013;9(1):127-31.

15. Anuk D, Alçalar N, Kaytan Sağlam E, Bahadır G. Onkoloji alanında çalışan hekimlerin perspektifinden ölüme ilişkin tutumlar ve kötü haber verme ilişkisi. Poster Sunumu (PS-089) 13. Ulusal Radyasyon Onkolojisi Kongresi Bildiri Kitapçı̆̆ 2018;86.

16. Kübler-Ross E. On death and dying. Routledge; 1973.

17. Fesci HB, Ünal S. Kanserli Hastaların Kötü Haber Almaya İlişkin Görüşleri. TAF Prev Med Bull 2011;10(3):319-26.

18. Matthews T, Baken D, Ross K, Ogilvie E, Kent L. The Experiences of Patients and their Family Members when Receiving Bad News about Cancer: A Qualitative Meta-synthesis. Psychooncology 2019;28(12):2286-94.

19. Buckman R, Kason Y. How to break bad news - a practical protocol for healthcare professionals. 1st ed. Toronto: University of Toronto Press; 1992.

20. Baile WF1, Buckman R, Lenzi R, Glober G, Beale EA, Kudelka AP. SPIKES-a six-step protocol for delivering bad news: application to the patient with cancer. Oncologist 2000;5(4):302-11.

21. VandeKieft GK. Breaking bad news. Am Fam Physician 2001;64(12):1975-8.

22. Narayanan V, Bista B, Koshy C. "BREAKS" Protocol for Breaking Bad News. Indian J Palliat Care 2010;16(2):61-5.

23. Marschollek P, Bąkowska K, Bąkowski W, Marschollek K, Tarkowski R. Oncologists and breaking bad newsFrom the informed patients' point of view. The evaluation of the SPIKES protocol implementation. J Cancer Educ 2019;34(2):375-80.

24. Kalanithi P. Son nefes havaya karışmadan. 5th ed. İstanbul: Altın Kitaplar Yayınevi; 2016. 